\title{
Application of One-Step IADPSG Versus Two-Step Diagnostic Criteria for Gestational Diabetes in the Real World: Impact on Health Services, Clinical Care, and Outcomes
}

\author{
Florence M. Brown $^{1,2}$ • Jennifer Wyckoff ${ }^{3}$
}

Published online: 10 August 2017

(C) The Author(s) 2017. This article is an open access publication

\begin{abstract}
Purpose of Review This paper seeks to summarize the impact of the one-step International Association of Diabetes and Pregnancy Study Groups (IADPSG) versus the two-step gestational diabetes mellitus (GDM) criteria with regard to prevalence, outcomes, healthcare delivery, and long-term maternal metabolic risk.

Recent Findings Studies demonstrate a 1.03-3.78-fold rise in the prevalence of GDM with IADPSG criteria versus baseline criteria. Women with GDM by IADPSG criteria have more adverse pregnancy outcomes than women with normal glucose tolerance (NGT). Treatment of GDM by IADPSG criteria may be cost effective. Use of the fasting glucose as a screen before the 75 -g oral glucose tolerance test to rule out GDM with fasting plasma glucose (FPG) $<4.4(80 \mathrm{mg} / \mathrm{dl})$ and rule in GDM with FPG $\geq 5.1 \mathrm{mmol} / \mathrm{l}(92 \mathrm{mg} / \mathrm{dl})$ reduces the need for OGTT by $50 \%$ and its cost and inconvenience. The prevalence of postpartum abnormal glucose metabolism is higher for women with GDM diagnosed by IADPSG criteria versus that for women with NGT.

Summary Data support the use of IADPSG criteria, if the cost of diagnosis and treatment can be controlled and if lifestyle can be optimized to reduce the risk of future diabetes.
\end{abstract}

Keywords GDM $\cdot$ IADPSG $\cdot$ Diagnosis $\cdot$ Prevalence $\cdot$ Outcomes $\cdot$ Cost

This article is part of the Topical Collection on Diabetes and Pregnancy

Florence M. Brown

Florence.brown@joslin.harvard.edu

Joslin Diabetes Center, 1 Joslin Pl, Boston, MA 02215, USA

2 Harvard Medical School, Boston, USA

3 University of Michigan, Ann Arbor, USA

\section{Introduction}

For well over 50 years, there has been a lack of consensus over the appropriate diagnostic criteria for gestational diabetes mellitus (GDM) and the significance of the diagnosis. Competing diagnostic criteria across the globe have complicated the delivery of healthcare and the design and interpretation of research in GDM $[1 \bullet 2]$. The Hyperglycemia and Adverse Pregnancy Outcomes (HAPO) study was intended to lead to unification and agreement on the diagnostic criteria for GDM [3]. In 2010, the International Association of Diabetes and Pregnancy Study Groups (IADPSG) released their recommendations for a new set of diagnostic criteria, based on the HAPO study outcomes [4]. However, an ongoing global debate continues about when and how to screen and diagnose GDM. A variety of local, regional, and institutional diagnostic criteria continues to be applied in practice, confusing both healthcare delivery and research $[1 \bullet, 5]$. This chapter seeks to review this history and explore the outcomes and impact of the IADPSG criteria.

\section{Evolution of the Diagnostic Criteria for GDM}

\section{O'Sullivan and Mahan}

In the 1960s, pregnancy was generally known to induce a state of reduced glucose tolerance. Whether this was pathologic was debated. How this should be assessed, by intravenous glucose tolerance test (IGTT) versus oral glucose tolerance test (OGTT), was also unclear. Furthermore, what glucose level should be considered abnormal was unknown.

At the 23rd annual meeting of the American Diabetes Association (ADA) in Atlantic City on June 16, 1963, John O'Sullivan and Clare Mahan from Boston City and the Boston 
Lying-In hospitals presented their landmark study demonstrating the ability of an OGTT performed during pregnancy to predict future risk of type 2 DM (DM2) [6]. They followed 752 women with baseline 100-g 3-h OGTTs performed at registration with the obstetric clinic, with periodic OGTTs for 8 years, and compared the predictive value of three glucose levels representing the 84.1 (level I), 97.7 (level II), and 99.9th (level III) percentiles $(1,2$, and 3SD above the mean, respectively). The authors considered two or more values that met or exceeded targets to be a positive test. They reported that the cumulative incidence of DM2 after approximately 8 years was $17.2 \%$ for level I, $29 \%$ for level II, and $60.1 \%$ for level III. The authors chose the level II criteria (2SD above the mean) as the best choice for predicting the development of DM2 as it reflected the results of the cortisone OGTT [7], a method shown at that time by Conn and Fajans to predict the development of DM2 and the prevalence of DM2 in a community [8]. Subsequently, a 16-year cumulative incidence of DM2 of $60 \%$ was demonstrated by life table analysis in the level 2 group [9]. A 1-h 50-g glucose challenge test (GCT) with whole blood glucose threshold of $7.2 \mathrm{mmol} / 1(130 \mathrm{mg} / \mathrm{dl})$ had $87 \%$ specificity and $79 \%$ sensitivity for stratifying risk in a population with $2.5 \%$ prevalence of GDM [9]. The O'Sullivan and Mahan paper (and its recommendation of "level II" criteria for the diagnosis of GDM) was the cornerstone of GDM diagnosis in the USA for the next 40 years. These criteria are described in Table 1.

\section{National Diabetes Data Group (NDDG)}

The O'Sullivan criteria were based on the measurement of glucose in whole blood [6]. Glucose measured in whole blood tended to be less accurate than glucose measured in plasma or serum in part because blood cells would metabolize about 5\% of the glucose in the sample per hour [10]. In the 1970s, laboratories moved to measure glucose in plasma. However, glucose measured in whole blood was generally $15 \%$ lower than glucose measured in plasma. So, the O'Sullivan criteria needed to be revised to reflect the change in glucose measurement. In 1979, the NDDG endorsed a revision of the O'Sullivan criteria reflecting this change in measurement technique [11].

\section{Carpenter and Coustan (CC)}

In 1982, Carpenter and Coustan suggested a new set of diagnostic criteria based on an adjustment of O'Sullivan's criteria taking into account the measurement of plasma glucose using the glucose oxidase method instead of the previously used SomogyiNelson method [12]. This created two different interpretations of O'Sullivan and Mahan's criteria based on the 100-g OGTT in the USA. The CC criteria diagnosed 30-50\% more women with GDM than the NDDG criteria [13]. Recently, in a secondary analysis of Landon et al.'s landmark study of the impact of treatment of GDM, Harper found that those diagnosed by CC criteria benefitted equally from treatment compared with those diagnosed by NDDG criteria. The number needed to treat to prevent a single outcome of cesarean delivery (CS), pregnancy-induced hypertension (PIH), large-for-gestational-age infant (LGA), and macrosomia was 20 or less for the overall group and similar for both CC and NDDG criteria [13, 14].

\section{International Criteria}

While the two-step method using a 50-g GCT as a screening test followed by a 100-g OGTT (utilizing either CC or NDDG criteria) was widely adopted in the USA, much of the rest of the world preferred a one-step screening 75-g OGTT method. Between 1990 and 2005, there was a proliferation of competing international criteria, many based on a one-step method using a 75-g OGTT, with published guidelines from the European Association for the Study of Diabetes (EASD) in

Table 1 Major criteria for the diagnosis of GDM

\begin{tabular}{llllllll}
\hline & Sample & Steps & $\begin{array}{l}\text { OGTT } \\
\text { load }\end{array}$ & $\begin{array}{l}\text { No. } \\
\text { abnormal }\end{array}$ & $\begin{array}{l}\text { Fasting mg/ } \\
\text { dl } \\
(\mathrm{mmol} / \mathrm{l})\end{array}$ & $\begin{array}{l}1 \mathrm{~h} \mathrm{mg/dl} \\
(\mathrm{mmol} / \mathrm{l})\end{array}$ & $\begin{array}{l}2 \mathrm{~h} \mathrm{mg} / \mathrm{dl} \\
(\mathrm{mmol} / \mathrm{l})\end{array}$ \\
\hline O'Sullivan 1964 [6] & $\mathrm{B}$ & 2 & $100 \mathrm{~g}$ & $\geq 2$ & $90(5)$ & $165(9.2)$ & $145(8.1)$ \\
$(\mathrm{mmol} / \mathrm{l})$
\end{tabular}

$\mathrm{X}=$ not applicable

$\mathrm{B}=$ Whole blood

$\mathrm{P}=$ Plasma 
1996 [15], the Australasian Diabetes in Pregnancy Society (ADIPS) in 1998 [16], and the World Health Organization (WHO) in 1999 [17], among others [1 •, 18]. A large-scale study of maternal hyperglycemia and its relationship to fetal outcomes was needed to try to resolve these differences.

\section{The Hyperglycemia and Adverse Pregnancy Outcomes (HAPO) Study}

The HAPO study was designed with the goal to achieve consensus in the diagnosis of GDM by investigating the impact of maternal glycemia, less severe than overt diabetes, on the risk of adverse pregnancy and neonatal outcomes [3]. Consistent with previous studies $[19,20]$, the HAPO study demonstrated a linear increase in the risk of primary outcomes (LGA, cord C-peptide, clinical neonatal hypoglycemia (NH), and primary CS) with increasing degrees of hyperglycemia, as assessed by a fasting 75-g OGTT at fasting, 1 and $2 \mathrm{~h}$. Secondary outcomes of preterm delivery (PTD) < 37 weeks' gestation, shoulder dystocia/birth injury, and preeclampsia also increased with increasing glucose levels [3] as did neonatal skinfold thicknesses $>90 \%$ [21].

\section{The International Association of Diabetes in Pregnancy Study Groups (IADPSG)}

The IADPSG convened a consensus conference in June 2008 with the goal of reaching international consensus regarding the challenging aspects of the diagnosis of GDM, including:

1) How to use the HAPO findings to create diagnostic criteria for GDM based on pregnancy and neonatal outcomes

2) How to establish the one-step 75-g OGTT as the preferred international diagnostic test for GDM

3) How to screen and diagnose preexisting DM (PEDM) in the first trimester

The IADPSG recommendations were published in 2010 [4].

1) How to use the outcomes from HAPO to create a diagnostic criteria for GDM based on pregnancy and neonatal outcomes

The first challenge was to establish dichotomous targets for the fasting, 1- and 2-h values even though the risks of adverse outcomes demonstrated strong linear relationships with these variables. An odds ratio of 1.75 times the mean was selected for the outcomes of increased neonatal body fat, LGA, and cord c-peptide greater than the 90th percentile to arrive at the recommended diagnostic criteria for GDM. The plasma glucose levels corresponding to or above an OR of 1.75 were fasting $\geq 5.1 \mathrm{mmol} / \mathrm{l}(92 \mathrm{mg} / \mathrm{dl}) ; 1 \mathrm{~h} \geq 10 \mathrm{mmol} / 1(180 \mathrm{mg} /$ $\mathrm{dl}) ; 2 \mathrm{~h} \geq 8.5 \mathrm{mmol} / \mathrm{l}(153 \mathrm{mg} / \mathrm{dl})$ [4]. GDM was diagnosed if one or more values were met and were less than the criteria for overt diabetes [4]. Using these criteria, the prevalence of GDM in the collaborating HAPO centers ranged from 9.3$25.5 \%$, with an average of $17.8 \%$ for the study overall [22]. The chosen cutoffs were necessarily arbitrary and based on expert opinion. In part, due to the linear relationship of glucose levels with higher frequencies of adverse outcomes, the choice of IADPSG thresholds has been debated, balancing risks and costs against benefit.

2) Establish the one-step 75-g OGTT over the two-step 100$\mathrm{g}$ OGTT as the preferred international diagnostic test for GDM

A survey of IADPSG members indicated that $60 \%$ opted for the one-step method, while $30 \%$ preferred the two-step method [23]. However, to convince healthcare delivery institutions and health professional associations that advocate the highest standards of practice that the one-step 75-g OGTT is superior to the two-step 100-g OGTT for the diagnosis of GDM, studies are needed to demonstrate the effect of treatment on short-term pregnancy and neonatal outcomes, as well as long-term cardiometabolic benefits to mother and offspring and the cost effectiveness of treatment.

3) Make recommendations on how to screen and diagnosis PEDM in the first trimester

The American Congress of Obstetricians and Gynecologists (ACOG) acknowledged that the benefit of treatment of GDM identified early in pregnancy has not been demonstrated but rather has been accepted on a theoretical basis [24]. Prior to the IADPSG recommendations, ACOG recommended two-step screening for GDM in the first trimester for women considered to be high risk [24]. Risk factors for GDM include the following: $>35$ years old, overweight or obese, chronic hypertension or polycystic ovarian syndrome, prior GDM, strong family history of diabetes, stillbirth in a previous pregnancy, and high-risk racial/ethnic group (African American, American Indian, Asian American, Hispanic, Latina, or Pacific Islander).

At the IADPSG conference, there was consensus on the need to diagnose women meeting criteria for PEDM in the first trimester defined by fasting plasma glucose (FPG) $\geq 7.0 \mathrm{mmol}(126 \mathrm{mg} / \mathrm{dl})$, random blood glucose (RBG) $\geq 11.1 \mathrm{mmol} / 1(200 \mathrm{mg} / \mathrm{dl})$, or hemoglobin A1c (A1c) $\geq 48 \mathrm{mmol} / \mathrm{mol}(6.5 \%)$, but there was no consensus on universal early screening [4]. They defined early diagnosis of GDM based on the same criteria for GDM later in pregnancy, if not diagnostic of PEDM, with FPG $\geq 5.1 \mathrm{mmol} / \mathrm{l}(92 \mathrm{mg} / \mathrm{dl})$ but $\leq 7.0 \mathrm{mmol} / \mathrm{l}(126 \mathrm{mg} / \mathrm{dl})$. If early pregnancy $\mathrm{FPG}$ was $\leq 5.1 \mathrm{mmol} / 1(92 \mathrm{mg} / \mathrm{dl})$, they recommended repeat testing for GDM from 24 to 28 weeks' gestation with a 75-g OGTT. 
They acknowledged that there was no data to support this recommendation.

The IADPSG criteria were erratically adopted for both the first trimester and 24-28-week screening, and instead of creating consensus, they became yet another set of competing criteria, which further added to the confusion.

\section{NIH Consensus Conference}

Following the release of the IADPSG recommendations, an NIH Consensus Conference was convened to respond to the controversies in the screening and diagnosis of GDM [25]. In preparation, the Agency for Healthcare Research and Quality (AHRQ) contracted with the University of Alberta Evidence-based Practice Center to create an evidence-based report on this topic [26]. Their search identified 14,398 citations and included 97 studies (6 randomized controlled trials (RCTs), 63 prospective cohort studies, and 28 retrospective cohort studies).

This exhaustive review revisited some of the key points of GDM diagnosis and the IADPSG consensus recommendations. In review of the first trimester screening for PEDM, they found limited evidence for or against early screening $[25,26]$. For universal second trimester screening, they concluded that while there was clear evidence of worsening pregnancy and neonatal outcomes with increasing levels of glucose, there was no adequate data to support a one-step 75-g OGTT over the two-step 100-g OGTT [25, 26]. Financial implications were not addressed.

\section{Impact of the Application of IADPSG Criteria}

\section{Prevalence of GDM With the Application of IADPSG Criteria}

The prevalence of GDM using consistent criteria over time has been increasing globally, mirroring the epidemic of DM2 and obesity [27, 28]. Comparing GDM prevalence between countries has been confounded by differing sets of diagnostic criteria. In an illustrative 2012 international survey, Jiwani details the huge variation in screening practices [5]. HAPO provided some of the first robust international comparisons of GDM prevalence. Applying the IADPSG criteria retrospectively to the HAPO study population, the frequency of GDM was $17.8 \%$ overall, with a range from 9.3 to $25.5 \%$ in the collaborating centers [22]. The IADPSG consensus panel had predicted that the prevalence of GDM using the IADPSG criteria would be higher compared with that of most other criteria in use throughout the world. So, the introduction of IADPSG criteria led to a plethora of data looking at local prevalence of GDM [1•, 18, 29-32, 33••, 34-47]. Figure 1 compares reported prevalence rates for GDM from various countries using the IADPSG criteria in comparison to the criteria previously applied in that country. The reported prevalence of GDM using IADPSG criteria varied from 3.5 to $45.3 \%[1 \bullet, 39]$. IADPSG universally increased the prevalence. The absolute increase was by as much as $33 \%$ [1•]. Figure 2 shows the fold change from baseline criteria ranged from 1.03 to $3.78[1 \bullet, 18,29-32,33 \bullet \bullet, 34-47]$. Table 2 describes the data.

In two elegant studies, authors compared the prevalence of GDM in their respective hospitals, using a variety of criteria: ADA 2003, ADIPS 1998, CDA 2013, European Association for the Study of Diabetes (EASD) 1996, IADPSG 2010, NZSSD 2004, and WHO 1999 [1•, 18]. In the Bulgarian study, 800 women were screened using a 75-g OGTT [18]. The prevalence of GDM varied from $10.8 \%$ using the EASD criteria to $31.6 \%$ using the IADPSG criteria. In the United Arab Emirates (UAE), 2337 women were screened with a 75-g OGTT between 24 and 28 weeks' gestation [1•]. Most $(97.6 \%)$ of this study population were either of Arabic or Indian descent. A historical data set from the same hospital in 2010 when the 100-g two-step method was being applied was used to compare prevalence to NDDG and CC criteria. Prevalence using the one-step method ranged from $9.2 \%$ (CDA 2003) to $45.3 \%$ (IADPSG), a 5-fold difference. Furthermore, use of IADPSG criteria resulted in a 6-fold higher prevalence compared to a historical prevalence of $7.7 \%$, when NDDG criteria were applied.

Two Norwegian studies demonstrate that there are aspects to study design other than diagnostic criteria that need to be considered when trying to understand the differences in the prevalence of GDM between studies, including percentage of population screened, universal versus selective screening, and gestational age at testing [29, 32]. In an analysis of data from a previously reported RCT of a structured exercise program to prevent GDM, 852 Caucasian women were screened using a 75-g OGTT between 18 and 22 weeks and then again between 32 and 36 weeks [32]. The prevalence of GDM at 32-36 weeks was $6.1 \%$ for WHO criteria versus $7.4 \%$ for IADPSG criteria. IADPSG criteria resulted in only a 1.2 -fold increase in prevalence of GDM over WHO 1999 criteria. In total, 73 women (10.6\%) were diagnosed with GDM: 22 by WHO only, 31 by IADPSG only, and 20 (27\%) by both. Important considerations in the design of this study include the ethnic composition, the population being drawn from a group of women voluntarily participating in an exercise study which excluded high-risk pregnancies, the exercise intervention of the study itself, etc.

In a second population-based cohort study from Norway, 759 pregnant women $(59 \%$ of whom were from ethnic minorities), were screened at 26-30 weeks using modified IADPSG criteria [29]. A 2.4 times greater GDM prevalence was found using IADPSG of $31.5 \%$ compared to $13 \%$ when WHO 1999 
Reported Prevalence of GDM by Country Using IADPSG criteria

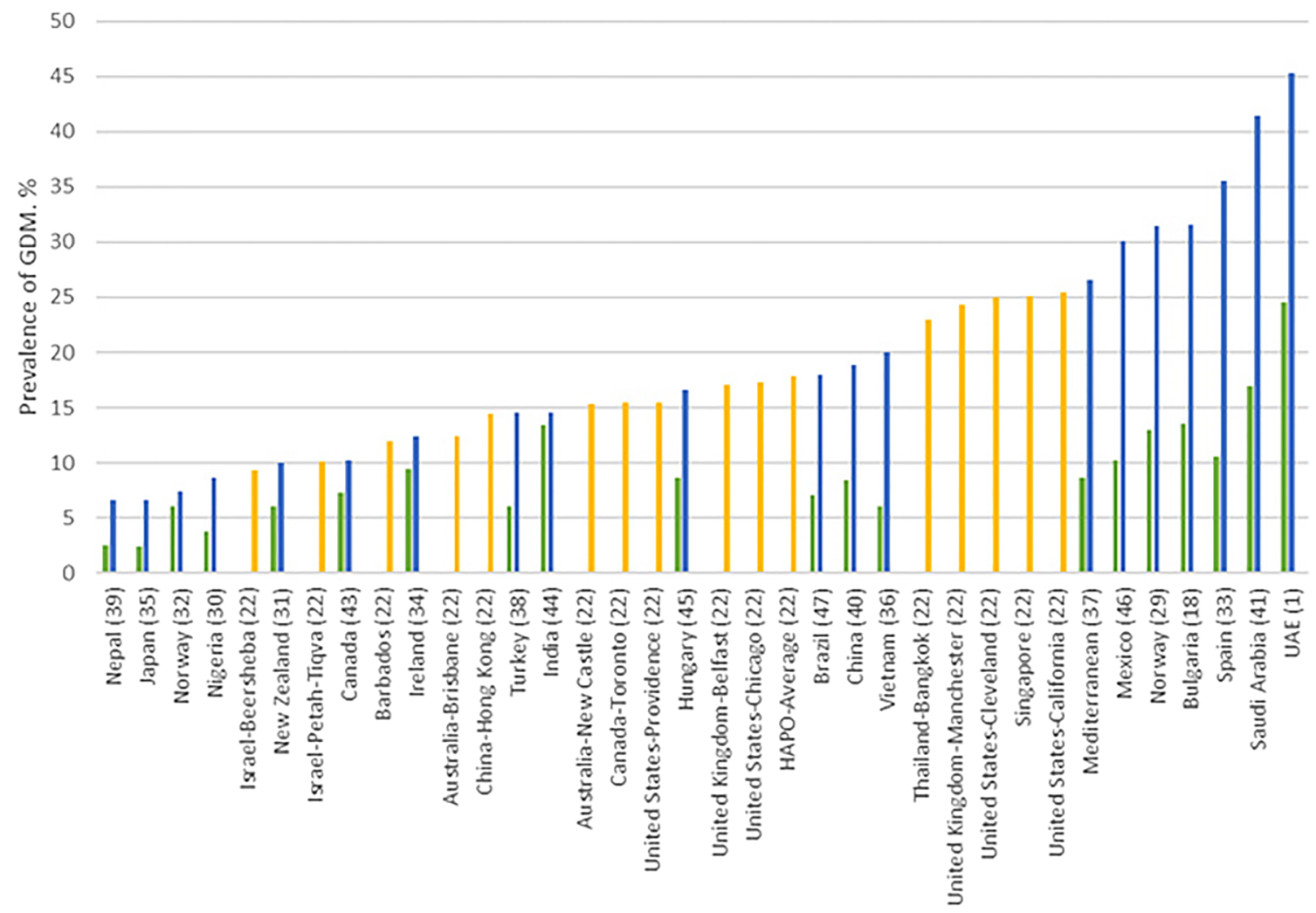

Location

ay Previous Criteria

BBY IADPSG IHAPO

Fig. 1 Prevalence of GDM by country using the IADPSG criteria

criteria were applied. If only the subset of women of Western European origin was analyzed, the prevalence with IADPSG was 24\% and that with WHO 1999 11\%.
In summary, studies demonstrate a 1.03-3.78-fold rise in the prevalence of GDM with the IADPSG criteria compared with baseline criteria.

Fig. 2 Fold change in prevalence
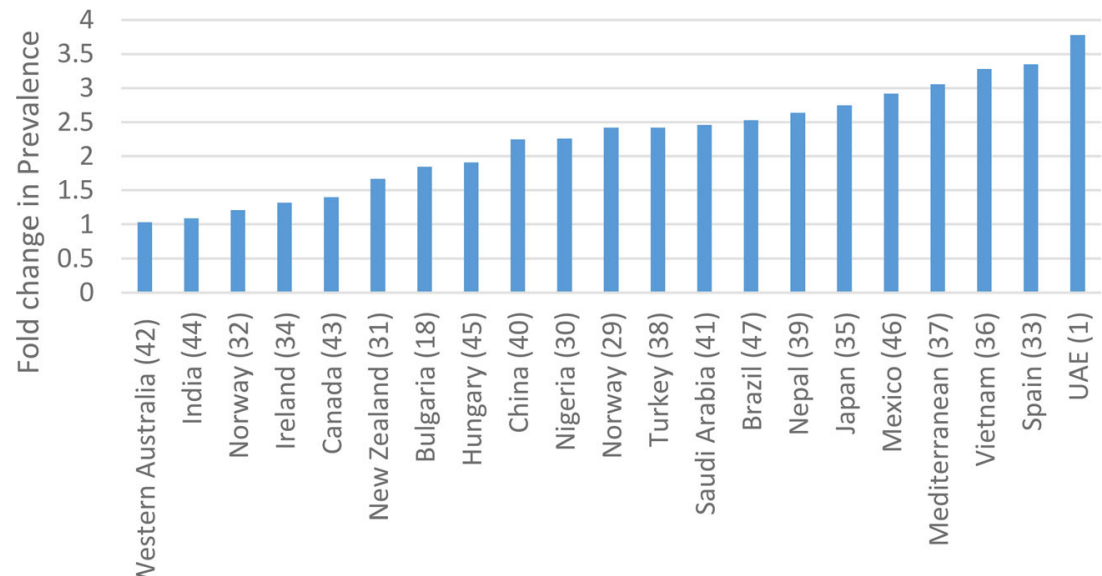
Table 2 Change in prevalence of GDM using the IADPSG criteria

\begin{tabular}{|c|c|c|c|c|c|c|}
\hline \multirow[t]{2}{*}{ Country } & \multicolumn{3}{|c|}{ Baseline prevalence } & \multirow[t]{2}{*}{ IADPSG } & \multirow{2}{*}{$\begin{array}{l}\text { Absolute change from } \\
\text { local reference criteria }\end{array}$} & \multirow{2}{*}{$\begin{array}{l}\text { Fold change from } \\
\text { local criteria }\end{array}$} \\
\hline & $\mathrm{ADA}^{\mathrm{a}}$ & $\mathrm{WHO}^{\mathrm{b}} 1999$ & Regional & & & \\
\hline Norway [29] & & $13 \%$ & & $31.5 \%^{\mathrm{a}}$ & $+18.5 \%$ & 2.42 \\
\hline $\mathrm{UAE}[1 \bullet]$ & $12 \%$ & $24.5 \%$ & & $45.3 \%$ & $+33.3 \%$ & 3.78 \\
\hline Nigeria [30] & & $3.8 \%$ & & $8.6 \%$ & $+4.8 \%$ & 2.26 \\
\hline New Zealand [31] & & & $6 \%^{\mathrm{c}}$ & $10 \%$ & $+4 \%$ & 1.67 \\
\hline Norway [32] & & $6.1 \%$ & & $7.4 \%^{\mathrm{a}}$ & $+1.3 \%$ & 1.21 \\
\hline Brazil [47] & & $7.1 \%$ & & $18 \%$ & $+10.9 \%$ & 2.53 \\
\hline Spain $[33 \bullet \bullet]$ & $10.6 \%$ & & & $35.5 \%$ & $+24.9 \%$ & 3.35 \\
\hline Ireland [34] & & $9.4 \%$ & & $12.4 \%$ & $+3 \%$ & 1.32 \\
\hline Japan [35] & & & $2.4 \%^{\mathrm{d}}$ & $6.6 \%$ & $+4.2 \%$ & 2.75 \\
\hline Vietnam [36] & $6.1 \%$ & & & $20 \%$ & $+13.9 \%$ & 3.28 \\
\hline Mediterranean [37] & $8.7 \%$ & & & $26.6 \%$ & $+17.9 \%$ & 3.06 \\
\hline Turkey [38] & $6 \%$ & & & $14.5 \%$ & $+8.5 \%$ & 2.42 \\
\hline Nepal [39] & & $2.5 \%$ & & $6.6 \%$ & $+4.1 \%$ & 2.64 \\
\hline China [40] & $8.4 \%$ & & & $18.9 \%$ & $+10.5 \%$ & 2.25 \\
\hline Saudi Arabia [41] & & & $16.9 \%^{\mathrm{e}}$ & $41.5 \%$ & $+24.6 \%$ & 2.46 \\
\hline Western Australia [42] & & & $3.4 \%^{\mathrm{f}}$ & $3.5 \%$ & $+0.1 \%$ & 1.03 \\
\hline Canada [43] & & & $7.3 \%^{\mathrm{g}}$ & $10.2 \%$ & $+2.9 \%$ & 1.40 \\
\hline India [44] & & $13.4 \%$ & & $14.6 \%$ & $+1.2 \%$ & 1.09 \\
\hline Hungary [45] & & $8.7 \%$ & & $16.6 \%$ & $+7.9 \%$ & 1.91 \\
\hline Mexico [46] & $10.3 \%$ & & & $30.1 \%$ & $+19.8 \%$ & 2.92 \\
\hline Bulgaria [18] & $13.5 \%$ & $17.1 \%$ & & $31.6 \%$ & $+18.1 \%$ & 1.85 \\
\hline
\end{tabular}

${ }^{\mathrm{a}}$ Two-step 100-g OGTT using either CC or NDDG criteria

${ }^{\mathrm{b}}$ World Health Organization (WHO)

${ }^{\mathrm{c}}$ Using New Zealand Society for the Study of Diabetes (NZSDD) criteria

${ }^{\mathrm{d}}$ Using Japan Society for Obstetrics and Gynecology (JSOG) criteria

${ }^{\text {e }}$ Two-step ADA criteria but a 75-g OGTT

${ }^{\mathrm{f}}$ Using Australasian Diabetes in Pregnancy Society (ADIPS) criteria

${ }^{\mathrm{g}}$ Using Canadian Diabetes Association (CDA) 2008

\section{Impact of One-Step IADPSG Versus Two-Step Diagnostic Criteria for Gestational Diabetes on Outcomes}

Treatment of GDM has been shown to reduce adverse outcomes [14, 48]. The Australian Carbohydrate Intolerance Study in Pregnant Women (ACHOIS) demonstrated that pregnancies in women diagnosed with GDM using the WHO 1999 criteria and randomized to treatment with education, diet, and, if necessary to achieve goals, insulin resulted in lower rates of serious perinatal complications ( 1 vs $4 \%, p=0.01$ ), macrosomia (10 vs $21 \%, p<0.001$ ), and preeclampsia (12 vs $18 \%, p=0.02$ ) [48]. In a study based in the USA, Landon et al. demonstrated that pregnancies in women diagnosed with GDM using the $\mathrm{CC}$ criteria and randomized to treatment with education, diet, and, if necessary to achieve goals, insulin resulted in lower rates of macrosomia (5.9 vs $14.3 \%, p<0.001)$ and preeclampsia (8.6 vs $13.6 \%, p=0.01)$ [14].
After the publication of the IADPSG criteria, several studies investigated the risk of adverse outcomes in pregnancies complicated by GDM using the new criteria. Prospective observational studies [36, 38, 49•] and a retrospective observational study [50] comparing women diagnosed with GDM using the IADPSG criteria but untreated (excluding those who also met CC criteria) to women with NGT found an increased risk of polyhydramnios [38], preeclampsia [49•], PTD [36], primary CS [49•], neonatal hypoglycemia [36], LGA [49•, 50], cord C-peptide [49•], and newborn percentage body fat above the 90th percentile [49•]. Infants also had higher ponderal index and $z$ scores [50]. Women with untreated GDM by IADPSG criteria had larger birth weight infants than women with treated GDM by CC criteria [50].

A prospective study comparing untreated women diagnosed with GDM using the IADPSG criteria (excluding those who met WHO criteria) to women with NGT found higher rates of preeclampsia, polyhydramnios, 
LGA, CS, neonatal intensive care (NICU) admission, and neonatal hypoglycemia [51].

Studies comparing women diagnosed with GDM using the IADPSG criteria but untreated (excluding other regional criteria) to women with NGT also found higher risk of adverse outcome [35, 43, 52] with one exception [53].

A retrospective cohort study investigated the impact of different glycemic thresholds on outcomes in women screened with a 75-g 2-h OGTT [54]. Glycemic thresholds were based on outcomes of the HAPO study (OR 1.75 (GDM1) vs OR > 2.0 (GDM2)). Women with one abnormal value were not treated. Women were excluded and treated if they had two abnormal values exceeding fasting $\geq 5.5 \mathrm{mmol} / \mathrm{l}(100 \mathrm{mg} / \mathrm{dl}) ; 1-\mathrm{h} 10.6 \mathrm{mmol} / \mathrm{l}(195 \mathrm{mg} / \mathrm{dl})$; and 2-h $8.9 \mathrm{mmol} / \mathrm{l}(160 \mathrm{mg} / \mathrm{dl})$. GDM1 had one abnormal glucose value in ranges for fasting 5.1-5.2 $\mathrm{mmol} / \mathrm{l}$ (92$94 \mathrm{mg} / \mathrm{l}) ; 1$-h 10-10.6 mmol/1 (180-190 mg/dl); 2-h 8.59.0 (153-162 mg/dl). GDM2 had one abnormal glucose value with fasting $\geq 5.3 \mathrm{mmol} / \mathrm{l}(95 \mathrm{mg} / \mathrm{l}), 1-\mathrm{h}>10.6 \mathrm{mmol} / \mathrm{l}$ ( $\geq 191 \mathrm{mg} / \mathrm{dl}), 2-\mathrm{h}>9.0 \mathrm{mmol} / \mathrm{l}(\geq 162 \mathrm{mg} / \mathrm{dl})$. Compared with NGT, GDM1 had increased birth weight and LGA. Compared with NGT, GDM2 had increased risk of preeclampsia/eclampsia, PTD, CS, shoulder dystocia, increased birthweight, LGA, and neonatal hypoglycemia. These findings indicate more adverse outcomes when HAPO glucose values for OR 2.0 are used as thresholds rather than IADPSG OR 1.75 thresholds. Authors cite the need for an RCT to determine benefit from treatment in these different groups of mild GDM [54].

Adverse outcomes of untreated GDM based on IADPSG criteria varied depending on whether the fasting glucose or the post glucose load was abnormal. An elevated fasting with normal post glucose load values was associated with increased LGA, while elevated post glucose loads with a normal fasting were associated with increased preterm delivery, gestational hypertension, and hyperbilirubinemia when compared with NGT [55].

Studies comparing the effects of treated GDM on outcomes for women diagnosed by IADPSG criteria versus prior/usual criteria including a modified 75-g CC [41], NDDG [56], or a modified two-step WHO 1999 [57] demonstrated similar pregnancy and neonatal outcomes as those diagnosed by $\mathrm{CC}$ and NDDG criteria, but greater risk of macrosomia and LGA compared with WHO criteria. These results suggest that IADPSG criteria may diagnose women with similar risk of adverse outcomes as CC and NDDG, but may identify women at higher risk of adverse outcomes than WHO. In addition, the treated IADPSG only group (excluding those diagnosed by modified CC criteria) had increased risk of CS, Apgar score $<7$ at $5 \mathrm{~min}$, and neonatal hypoglycemia compared with the NGT group [41].

Women diagnosed with GDM by IADPSG criteria had similar prevalence of risk factors as women diagnosed by $\mathrm{CC}$,
NDDG, or WHO criteria. Risk factors studied included South Asian high-risk ethnic group [29], prepregnancy overweight $[29,41]$, maternal age [32, 41], fasting insulin [32], no regular exercise [32], and one or more ACOG risk factors [56].

In summary, women diagnosed with GDM by IADPSG criteria have higher risk of adverse pregnancy and neonatal outcomes and higher prevalence of risk factors than woman with NGT.

\section{Maternal Risk for Type 2 Diabetes Based on the IADPSG Criteria}

As noted, O Sullivan's original work was intended to predict the development of DM2 in the mother [6]. As diagnostic criteria evolved, further studies described the predictive ability of the varying sets of criteria. Women with a history of GDM had approximately a 50\% risk of developing type 2 DM within 7-10 years [58] of their pregnancy and a 7 times increased risk compared to women with NGT [59].

The IADPSG criteria have also been shown to predict maternal postpartum glucose abnormalities $[60 \bullet, 61]$. In the ATLANTIC-DIP study of white Europeans, the results of 75-g OGTTs at 12 weeks' postpartum were compared between 270 women with a history of GDM based on IADPSG criteria and 388 women with normal glucose tolerance during pregnancy [60•]. In total, at 12 weeks' postpartum, $15.6 \%$ of women with previous history of GDM demonstrated glucose abnormalities (14.1\% IFG and/or IGT and 1.5\% DM2) compared to $0.8 \%$ of women with no history of GDM. This cohort was followed for up to 5 years, (a mean follow-up for those with GDM of 2.6 years), and at repeat testing another $10.4 \%$ of those with a history of GDM had developed abnormal glucose levels compared to only $2.8 \%$ of those without history of GDM. This resulted in a cumulative percentage of $25.9 \%$ of those with a history of GDM having glucose abnormalities compared to only $3.6 \%$ of those with no history of GDM.

In a study of 305 ethnically homogenous Czech women, the postpartum prevalence of abnormal glucose in women diagnosed with GDM was 16.7\% [61]. Based on receiver operating curves (ROC) analysis, this study concluded that the IADPSG cutoff values performed better than WHO for risk stratification of postpartum glucose abnormality (Table 3).

In summary, studies up to 5 years' postpartum indicate an increased risk of impaired glucose metabolism in women who had GDM by IADPSG criteria, compared to that in women with NGT.

\section{Financial Implications of IADPSG}

The organizers of the Pasadena conference understood the IADPSG criteria would increase the prevalence of GDM. This invariably led to the question of the financial implications 
Table 3 Maternal risk of type 2 diabetes based on IADPSG criteria

\begin{tabular}{lllllll}
\hline DM criteria & Ref & Ethnicity & Time point & $\begin{array}{l}\text { No GDM, risk } \\
\text { of IFG/IGT, } \%\end{array}$ & $\begin{array}{l}\text { GDM, risk } \\
\text { of DM2, } \%\end{array}$ & $\begin{array}{l}\text { GDM, risk of } \\
\text { IFG/IGT, \% }\end{array}$ \\
\hline O'Sullivan & {$[6]$} & US & 8 years & Not reported & 29 & Not reported \\
O’Sullivan & {$[9]$} & US & 16 years & Not reported & 60 & Not reported \\
NDDG & {$[84]$} & US & 6 weeks & Not reported & 2.6 & 6.8 \\
IADPSG & {$[60 \bullet$} & Irish & 12 weeks & 0.8 & 1.5 & 14.1 \\
IADPSG & {$[60 \bullet$} & Irish & 2.5 years & 3.6 & Not reported & 25.9 \\
IADPSG & {$[61]$} & Czech & 12 weeks & Not reported & 5.2 & 10.5 \\
\hline
\end{tabular}

and cost effectiveness of treating those diagnosed by the new set of criteria.

In 2012, Agarwal et al. compared the costs and laboratory work load units (WLUs) of using the 50-g GCT screening test followed by the 100-g OGTT using CC criteria with the one-step 75-g OGTT in a high-risk population in the UAE [62•]. In a 12month study, 1101 women were tested. Standard insurance billing was $\$ 18.60$ for a $50-\mathrm{g}$ GCT and $\$ 50$ for either a 75 - or $100-\mathrm{g}$ OGTT. Testing under the one-step method resulted in $\$ 55,250$ in billing compared to $\$ 31,985$ using the two-step method. However, annual WLUs were only 18,662 using the one-step method versus 28,975 using the two-step method. They concluded that adoption of the one-step method would increase the cost by $42 \%$ but would decrease laboratory workload by $36 \%$.

In a cost-effectiveness analysis, Mission et al. compared the one-step IADPSG criteria versus the two-step CC criteria using a Monte Carlo simulation to assess cost, effectiveness, and cost-effectiveness based on probabilities, costs, and benefits derived from the literature [63]. Using IADPSG guidelines proved more expensive but also more effective and more cost effective (\$61,503/quality adjusted life year (QALY)). Sensitivity analysis determined that preeclampsia and CS were the two outcomes that had the greatest impact on cost effectiveness. A decision analytic model showed that IADPSG guidelines were cost effective if the costs to treat GDM were $<\$ 2630$ and efficacy was at least $74.9 \%$ of expected efficacy and if at least $2 \%$ more patients are diagnosed with GDM. Similarly, Werner et al. found that the one-step method was also cost effective compared to the two-step method at $\$ 20,336$ per QALY if postdelivery counseling and behavior modification were provided to reduce future diabetes risks [64].

Duran et al. concluded that $€ 14,358.06$ could be saved per 100 women using IADPSG versus CC to diagnose GDM [33••]. They estimated that the new criteria would increase treatment costs by $€ 3753.79$, but reduce laboratory costs by $€ 1587.76$, and further reduce delivery and NICU costs by $€ 16,336.90$. Most cost savings were related to a predicted reduction in CS and NICU admissions.

In a systemic review of these issues, Weile et al. found that 12 out of 100 studies between 2002 and 2013 had full economic evaluations [65]. They emphasized that long-term benefits of treating GDM and preventing maternal DM2 should be included in cost-effectiveness analysis for GDM. However, they were unable to recommend any particular GDM screening and diagnostic criteria for global recommendation, due to the high variability in the methodology and results of the studies.

\section{Acceptance and Endorsements of IADPSG}

The ADA endorsed the IADPSG guidelines in 2011 [66]. Both the Endocrine Society and the WHO adopted them in 2013 [67, 68]. However, ACOG continued to recommend the two-step method in a 2011 Committee Opinion [69] and in their 2013 Practice Bulletin citing the concern that approximately $18 \%$ of women would be diagnosed with GDM based on IADPSG guidelines [70]. The ACOG 2013 position was based in part on recommendations from the NIH Consensus Conference.

\section{Remaining Debates Over the Application of Diagnostic Criteria}

\section{Universal Screening Versus Selective Screening}

Both the 50-g GCT and the OGTT are unpleasant, timeconsuming, and expensive tests. If selective screening based on risk factors could reliably predict those not at risk for GDM, it would reduce costs and patient discomfort. Risk factors for GDM differ depending on criteria used. ACOG includes previous history of GDM, previous history of macrosomia, maternal age, maternal obesity, ethnicity, family history of DM2, multiple gestation, and polycystic ovarian syndrome [70]. While risk factor screening for GDM can be effective at identifying women at risk, the prevalence of these risk factors is unfortunately so high in the USA that using the ADA risk factor criteria [71] as endorsed by ACOG [70] would result in $\geq 90 \%$ of women requiring screening [72].

Another study demonstrated that $91 \%$ of women with GDM and $80 \%$ of women with NGT had one or more risk factors for GDM [60•]. The prevalence of risk factors in the 
general population varied depending on which risk factor criteria were being used with ADA having better sensitivity and specificity than NICE and Irish, but still only achieving sensitivity $80 \%$ and specificity $44 \%$ when BMI $\geq 25 \mathrm{~kg} / \mathrm{m}^{2}$ was included as a risk factor [73].

In Nigeria, selective screening would have missed $20 \%$ of GDM cases [30]. ACOG acknowledged that as only $10 \%$ of the population would have been exempted from screening based on risk factors many physicians may elect to screen all pregnant patients as a practical matter [24].

\section{First Trimester Screening of Preexisting Diabetes and the Early Diagnosis of GDM With Worse Outcomes}

Studies using either HbA1c, FPG, or FPG followed by a 75-g 2-h OGTT (IADPSG criteria) support early pregnancy screening to diagnose women with PEDM, at high risk of GDM later in pregnancy, greater need for pharmacotherapy, and increased risk of poor outcomes [74-77].

Early pregnancy A1c $\geq 41 \mathrm{mmol} / \mathrm{mol}(5.9 \%)$ is associated with worse outcomes including increased risk of congenital malformations, preeclampsia, shoulder dystocia, and perinatal death [74]. It identified all the patients in the cohort who had overt diabetes. Women with A1c $\geq 41 \mathrm{mmol} / \mathrm{mol}(5.9 \%)$ represented only $2.9 \%$ of the total cohort. However, among women with $\mathrm{A} 1 \mathrm{c} \geq 41 \mathrm{mmol} /$ mol (5.9\%), early in pregnancy, $74 \%$ had GDM (diagnosed by IADPSG/WHO criteria either early or later in pregnancy) or overt diabetes (10.4\% of this group). As noted above, the sensitivity of diagnosing women with overt diabetes was $100 \%$. However, the sensitivity was not as good at diagnosing GDM, as $12 \%$ of women with Alc $<41 \mathrm{mmol} / \mathrm{mol}(5.9 \%)$ met the criteria for GDM earlier than 20 weeks and $12.8 \%$ met criteria later than 20 weeks, underscoring the need for either a one-step or two-step screen at 24-28 weeks in women with an early pregnancy A $1 \mathrm{c}<41 \mathrm{mmol} / \mathrm{mol}(5.9 \%)$.

While IADPSG recommended that first trimester $\mathrm{FPG} \geq 5.1 \mathrm{mmol} / \mathrm{l}(92 \mathrm{mg} / \mathrm{dl})$ be consistent with the diagnosis of GDM, a study by Zhu and Yang demonstrated that FPG declines in pregnancy, so that a first trimester FPG $<6.1 \mathrm{mmol} / \mathrm{l}(110 \mathrm{mg} / \mathrm{dl})$ is less predictive of GDM later in pregnancy [75]. While first trimester FPG 5.1-6.1 mmol/1 (92 to $<110 \mathrm{mg} / \mathrm{dl}$ ) is also associated with a higher risk of GDM, the incidence may not be sufficient to warrant early detection of GDM. The authors recommend identifying women with FPG $6.1-6.9 \mathrm{mmol} / 1(110-125 \mathrm{mg} / \mathrm{dl})$ for early intervention, as $66.2 \%$ will develop GDM later in pregnancy. They suggest this as a practical approach as there is no RCT outcome data to support early intervention in this intermediate range of glucose values.

A RCT designed to pick the best approach to screening for first trimester GDM compared FPG values 5.1-
$6.9 \mathrm{mmol} / \mathrm{l}(92-125 \mathrm{mg} / \mathrm{dl})$, followed by parallel randomization, to either a two-step $50-\mathrm{g}(7.8 \mathrm{mmol} / 1(140 \mathrm{mg} / \mathrm{dl})$ threshold) followed by a 100-g OGTT (CC thresholds) or a one-step 75-g 2-h OGTT (IADPSG criteria) and then rescreening at 24-28 weeks using the two-step method for initial GDM screen negatives [77]. ROC demonstrated that, in the first trimester, the one-step 75-g OGTT was a better predictor for GDM than the FPG test and two-step OGTT. The FPG test with a lower threshold of $5.1 \mathrm{mmol} / \mathrm{l}(92 \mathrm{mg} /$ dl) had more false-positive test results and was, therefore, less specific than the two other tests.

A study compared early screening at $<24$ weeks using either A1c $39-46 \mathrm{mmol} / 1$ (A1c $5.7-6.4 \%$ ) or FPG 5.1$6.9 \mathrm{mmol} / \mathrm{l}(92-125 \mathrm{mg} / \mathrm{dl})$ followed by a one-step $75-\mathrm{g}$ OGTT with IADPSG criteria at 24-28 weeks (early screen group) to the standard two-step method with CC criteria at 24-28 weeks (standard group) [76]. Prevalence of GDM in the early screening group was $9.4 \%$ versus that in the standard group $5.3 \%$. A greater percentage of women required pharmacotherapy in the early screening group.

\section{The Role of FPG Versus OGTT Versus A1c in Screening for GDM in the Third Trimester}

The FPG is a screening test candidate because of its high reproducibility [78].

In the HAPO study, risks of some adverse outcomes were low when FPG was $\leq 4.4 \mathrm{mmol} / \mathrm{l}(80 \mathrm{mg} / \mathrm{dl})$ [4]. However, it was thought that using FPG to potentially identify pregnancies at a very low risk for GDM and for adverse outcomes required further evaluation.

A systematic review for the United States Preventive Services Task Force (USPSTF) compared the FPG, A1c, and 50-g GCT at 24 weeks, as GDM screening tests. A FPG of $4.7 \mathrm{mmol} / 1(85 \mathrm{mg} / \mathrm{dl})$ had a sensitivity of $87 \%$ and a specificity of $52 \%$ [79]. In comparison, the GCT with a threshold of $7.8 \mathrm{mmol} / \mathrm{l}(140 \mathrm{mg} / \mathrm{dl})$ had sensitivity of $70-88 \%$ and specificity of $60-89 \%$. A threshold of $7.2 \mathrm{mmol} / 1(130 \mathrm{mg} /$ dl) had a sensitivity of $88-99 \%$ and specificity $66-77 \%$. A1c had the poorest test characteristics.

A retrospective study from China looked at outcomes of more than 25,000 women with FPG $\leq 4.4 \mathrm{mmol} / \mathrm{l}(80 \mathrm{mg} / \mathrm{dl})$ with treated versus untreated GDM by IADPSG criteria [80]. There was no difference in macrosomia (6.9 vs $7.2 \%$ ) or neonatal hypoglycemia treated (2.0 vs $1.7 \%$ ) in treated versus untreated pregnancies, respectively. There was an increased rate of CS in untreated GDM women (treated $48.4 \%$ vs untreated 59.7\%).

In a study of more than 1300 women, a strategy used the FPG threshold $>5.0 \mathrm{mmol} / \mathrm{l}(\geq 92 \mathrm{mg} / \mathrm{dl})(15.4 \%$ of the population) as the initial screening test to rule in GDM to reduce the need for OGTT and proceeding with full screen if FPG $\leq 5.0 \mathrm{mmol} / \mathrm{l}$ and $\mathrm{BMI}>25$ and age $>30$ years [37]. This 
would reduce full screening to $18.7 \%$ of the population achieving sensitivity $72.3 \%$ and specificity $79.8 \%$.

The strategy of Trujillo and others used the IADPSG criteria to rule in GDM with $\mathrm{FPG} \geq 5.1 \mathrm{mmol} / 1(92 \mathrm{mg} / \mathrm{dl})$ ( $15.2 \%$ or the population) and rule out GDM with FPG $\leq 4.4 \mathrm{mmol} / \mathrm{l}(80 \mathrm{mg} / \mathrm{dl})(54.3 \%$ of the population $)$ [81]. Only $38.7 \%$ of those with glucose in between these upper and lower limits for FPG required OGTT screening, eliminating the need in $61.3 \%$ of women. Sensitivity for diagnosing GDM by this method was $96.9 \%$. Sensitivity to predict adverse outcomes was $60 \%$.

Agarwal and others found that FPG could be used to diagnose GDM in $82.7 \%$ of a predominantly Arabic population [62 $]$. Similar to the study by Trujillo et al., this study used a FPG followed by a 75-g OGTT, if needed. If FPG $<4.4$ $(80 \mathrm{mg} / \mathrm{dl})$ rules out $\mathrm{GDM}$ or $\geq 5.1 \mathrm{mmol} / \mathrm{l}(92 \mathrm{mg} / \mathrm{dl})$ rules in GDM, then no additional testing is required. This avoids the need for 50\% of the OGTTs. The authors point out that in high-risk populations GCT adds an unnecessary screen and risks missing $20 \%$ with a false negative screen as well as those who do not show for the two-step OGTT (18\% in this study). Proceeding with a diagnostic test but using the fasting value to rule in or rule out GDM eliminates the need for the OGTT in $50 \%$. It is important to note that this is a predominantly Arabic population and there is variation in the fasting versus postprandial glucose patterns based on ethnicity.

Sevket et al. looked at the utility of the A1c in the diagnosis of GDM at 24-28 weeks' gestation [82]. GDM was diagnosed by IADPSG criteria, and a rule in/ rule out algorithm was used to evaluate the utility of A1c at 24 weeks as a screening tool to reduce the number of OGTTs. A lower Alc threshold of $27 \mathrm{mmol} / \mathrm{mol}$ (4.6\%) and higher threshold of $39 \mathrm{mmol} / \mathrm{mol}(5.7 \%)$ were determined based on ROC. Sensitivity using these thresholds was $94.4 \%$, but $33 \%$ would have been misclassified as having GDM. The algorithm only reduced the need for OGTT by $25 \%$. The authors concluded that the A1c is not a good screening test for GDM.

To summarize, the fasting glucose, as an initial screen for the one-step method to rule out GDM with FPG $<4.4$ $(80 \mathrm{mg} / \mathrm{dl})$ and to rule in GDM with FPG $\geq 5.1 \mathrm{mmol} / 1$ $(92 \mathrm{mg} / \mathrm{dl})$, reduces the need for OGTT by $50 \%$. It is a better screening tool than the GCT of the two step method which has $20 \%$ false negatives. The A1c is a poor screening test for GDM at 24-28 weeks.

\section{Conclusions}

Currently, ACOG lists both the NDDG and CC criteria for the diagnosis of GDM [70]. The ADA acknowledged the GDM screening and diagnosis controversy in their 2015 Practice Guidelines, and now recommends either the one- step IADPSG or the two-step method (either the NDDG or CC criteria) preferred by ACOG. However, recent data support the use of the CC criteria over NDDG criteria [13]. Outside the USA, the WHO and the International Federation of Gynecology and Obstetrics (FIGO) support the use of the IADPSG criteria [83]. Other varieties of responses to the IADPSG recommendations from the other nations also demonstrate the complexity and controversy, especially given concerns around access to healthcare and costs due to increases in the prevalence of GDM with the one-step IADPSG diagnostic criteria.

Studies of outcomes of women diagnosed with GDM based on the IADPSG criteria excluding other usual criteria demonstrate worse outcomes than those with NGT indicating a likely opportunity to improve outcomes with treatment. RCTs of treatment of GDM demonstrate reductions in adverse pregnancy and neonatal outcomes with treatment, although these studies did not use the exact GDM thresholds proposed by the IADPSG [14, 48]. The financial implications of IADPSG may be offset by lowering costs of diagnosis and treatment and improving effectiveness of treatment, particularly in higher risk populations. Counseling about long-term risks of diabetes and lifestyle prevention should be included in the treatment plan to further improve cost effectiveness. Universal screening has better sensitivity than risk factor screening. Appealing strategies to reduce the cost of screening that makes use of the fasting glucose in a rule out $<4.4 \mathrm{mmol} /$ $1(80 \mathrm{mg} / \mathrm{dl})$ or a rule in $\geq 5.1 \mathrm{mmol} / 1(92 \mathrm{mg} / \mathrm{dl})$ manner and proceeding with full diagnostic testing for in-between values provide high sensitivity and reduce the need for a full diagnostic testing in 50\% of women. The question of which 75-g 2-h OGTT glucose thresholds to use will continue to be debated due to the linear relationship between adverse pregnancy outcomes and glycemia. Use of the current IADPSG thresholds set at OR 1.75 of mean outcomes of HAPO with one abnormal value seems reasonable but small upward adjustments toward CC thresholds may help drive consensus.

First trimester screening methods may include the use of an A1c cutoff of $41 \mathrm{mmol} / \mathrm{mol}(5.9 \%)$ to identify all women with preexisting diabetes and women with high risk of GDM and adverse events. A first trimester fasting glucose threshold of $\geq 6.1 \mathrm{mmol} / \mathrm{l}(110 \mathrm{mg} / \mathrm{dl})$ may also be used to screen women with high risk of future GDM. Lower glucose targets $5.1-6.0 \mathrm{mmol} / 1(92-109 \mathrm{mg} / \mathrm{dl})$ recommended by IADPSG 2010 may have poor specificity to diagnose future GDM. Women who screen negative in the first trimester should be rescreened at 24-28 weeks. The role of the 50-g GCT for screening women who have already been identified as high risk of GDM in the first trimester is not substantiated. These women should go directly to diagnostic testing. Uses of local, regional, 
and institutional diagnostic criteria persist but steps should be taken to broaden consensus to use the onestep IADPSG criteria.

\section{Compliance with Ethical Standards}

Conflict of Interest Florence M. Brown and Jennifer Wyckoff declare that they have no conflict of interest.

Human and Animal Rights and Informed Consent All procedures performed in studies involving human participants were in accordance with the ethical standards of the institutional and/or national research committee and with the 1964 Helsinki declaration and its later amendments or comparable ethical standards. For retrospective studies formal consent is not required.

Open Access This article is distributed under the terms of the Creative Commons Attribution 4.0 International License (http:// creativecommons.org/licenses/by/4.0/), which permits unrestricted use, distribution, and reproduction in any medium, provided you give appropriate credit to the original author(s) and the source, provide a link to the Creative Commons license, and indicate if changes were made.

\section{References}

Papers of particular interest, published recently, have been highlighted as:

- Of importance

•. Of major importance

1. Agarwal MM, Dhatt GS, Othman Y. Gestational diabetes: differences between the current international diagnostic criteria and implications of switching to IADPSG. J Diabetes Complicat. 2015;29(4):544-9. Prevalence of GDM in a high-risk population using several different global criteria for the one-step method ranged from $9.2 \%$ (CDA 2003) to $45.3 \%$ (IADPSG), a 5-fold difference. Furthermore, use of IADPSG criteria resulted in a 6-fold higher prevalence compared to a historical prevalence of $7.7 \%$, when NDDG criteria were applied.

2. Sacks DB. Diagnosis of gestational diabetes mellitus: it is time for international consensus. Clin Chem. 2014;60(1):141-3.

3. Metzger BE, Lowe LP, Dyer AR, Trimble ER, Chaovarindr U, Coustan DR, et al. Hyperglycemia and adverse pregnancy outcomes. N Engl J Med. 2008;358(19):1991-2002.

4. Metzger BE, Gabbe SG, Persson B, Buchanan TA, Catalano PA, Damm $P$, et al. International association of diabetes and pregnancy study groups recommendations on the diagnosis and classification of hyperglycemia in pregnancy. Diabetes Care. 2010;33(3):676-82.

5. Jiwani A, Marseille E, Lohse N, Damm P, Hod M, Kahn JG. Gestational diabetes mellitus: results from a survey of country prevalence and practices. J Matern Fetal Neonatal Med. 2012;25(6):600-10.

6. O'Sullivan J. MC. Criteria for the oral glucose tolerance test in pregnancy. Diabetes (New York, NY). 1964;13:278-285.

7. Conn JW, Fajans SS. The prediabetic state: a concept of dynamic resistance to a genetic diabetogenic influence. Diabetes. 1962;11:335.

8. Wilkerson HL, Krall LP, Butler FK. Diabetes in a New England town. IV. 12-year progress report on the 70 diabetics found in the original Oxford, Mass., study. JAMA : the journal of the American Medical Association. 1962;179:652-4.

9. O'Sullivan JB. Establishing criteria for gestational diabetes. Diabetes Care. 1980;3(3):437-9.
10. McMillin J. Blood glucose. In: Walker HKHW, Hurst JW, editors. Clinical methods: the history, physical, and laboratory examinations. 3rd ed. Boston: Butterworths; 1990.

11. Classification and diagnosis of diabetes mellitus and other categories of glucose intolerance. Diabetes. 1979;28(12):1039-57.

12. Carpenter MW, Coustan DR. Criteria for screening tests for gestational diabetes. Am J Obstet Gynecol. 1982;144(7):768-73.

13. Harper LM, Mele L, Landon MB, Carpenter MW, Ramin SM, Reddy UM, et al. Carpenter-Coustan compared with National Diabetes Data Group Criteria for diagnosing gestational diabetes. Obstet Gynecol. 2016;127(5):893-8.

14. Landon MB, Spong CY, Thom E, Carpenter MW, Ramin SM, Casey B, et al. A multicenter, randomized trial of treatment for mild gestational diabetes. N Engl J Med. 2009;361(14):1339-48.

15. Brown CJ, Dawson A, Dodds R, Gamsu H, Gillmer M, Hall M, et al. Report of the Pregnancy and Neonatal Care Group. Diabetic medicine : a journal of the British Diabetic Association. 1996;13(9 Suppl 4):S43-53.

16. Hoffman L, Nolan C, Wilson JD, Oats JJ, Simmons D. Gestational diabetes mellitus - management guidelines. The Australasian Diabetes in Pregnancy Society. Med J Aust. 1998;169(2):93-7.

17. Definition, diagnosis and classification of diabetes mellitus and its complications. Geneva: World Health Organization; 1999.

18. Boyadzhieva MV, Atanasova I, Zacharieva S, Tankova T, Dimitrova V. Comparative analysis of current diagnostic criteria for gestational diabetes mellitus. Obstetric Medicine. 2012;5(2):71-7.

19. Sermer M, Naylor CD, Gare DJ, Kenshole AB, Ritchie JW, Farine $\mathrm{D}$, et al. Impact of increasing carbohydrate intolerance on maternalfetal outcomes in 3637 women without gestational diabetes. The Toronto Tri-Hospital Gestational Diabetes Project. Am J Obstet Gynecol. 1995;173(1):146-56.

20. Sacks DA, Greenspoon JS, Abu-Fadil S, Henry HM, Wolde-Tsadik G, Yao JF. Toward universal criteria for gestational diabetes: the 75gram glucose tolerance test in pregnancy. Am J Obstet Gynecol. 1995;172(2 Pt 1):607-14.

21. HAPO Study Cooperative Research Group. Hyperglycemia and Adverse Pregnancy Outcome (HAPO) study: associations with neonatal anthropometrics. Diabetes. 2009;58(2):453-9.

22. Sacks DA, Hadden DR, Maresh M, Deerochanawong C, Dyer AR, Metzger BE, et al. Frequency of gestational diabetes mellitus at collaborating centers based on IADPSG consensus panel-recommended criteria: the Hyperglycemia and Adverse Pregnancy Outcome (HAPO) study. Diabetes Care. 2012;35(3):526-8.

23. Ogunyemi DA, Fong A, Rad S, Fong S, Kjos SL. Attitudes and practices of healthcare providers regarding gestational diabetes: results of a survey conducted at the 2010 meeting of the International Association of Diabetes in Pregnancy Study Group (IADPSG). Diabet Med. 2011;28(8):976-86.

24. ACOG Practice Bulletin. Clinical management guidelines for obstetrician-gynecologists. Number 30, September 2001 (replaces Technical Bulletin Number 200, December 1994). Gestational diabetes. Obstet Gynecol. 2001;98(3):525-38.

25. Vandorsten JP, Dodson WC, Espeland MA, Grobman WA, Guise JM, Mercer BM, et al. NIH consensus development conference: diagnosing gestational diabetes mellitus. NIH consensus and state-of-the-science statements. 2013;29(1):1-31.

26. Hartling L, Dryden DM, Guthrie A, Muise M, Vandermeer B, Aktary WM, et al. Screening and diagnosing gestational diabetes mellitus. Evidence report/technology assessment. 2012;210:1-327.

27. Feig DS, Hwee J, Shah BR, Booth GL, Bierman AS, Lipscombe LL. Trends in incidence of diabetes in pregnancy and serious perinatal outcomes: a large, population-based study in Ontario, Canada, 1996-2010. Diabetes Care. 2014;37(6):1590-6.

28. Lavery JA, Friedman AM, Keyes KM, Wright JD, Ananth CV. Gestational diabetes in the United States: temporal changes in 
prevalence rates between 1979 and 2010. BJOG: An International Journal of Obstetrics \& Gynaecology. 2016:n/a-n/a.

29. Jenum AK, Morkrid K, Sletner L, Vangen S, Torper JL, Nakstad B, et al. Impact of ethnicity on gestational diabetes identified with the WHO and the modified International Association of Diabetes and Pregnancy Study Groups criteria: a population-based cohort study. Eur J Endocrinol. 2012;166(2):317-24.

30. Olagbuji BN, Atiba AS, Olofinbiyi BA, Akintayo AA, Awoleke JO, Ade-Ojo IP, et al. Prevalence of and risk factors for gestational diabetes using 1999, 2013 WHO and IADPSG criteria upon implementation of a universal one-step screening and diagnostic strategy in a sub-Saharan African population. Eur J Obstet Gynecol Reprod Biol. 2015;189:27-32.

31. Ekeroma AJ, Chandran GS, McCowan L, Ansell D, Eagleton C, Kenealy T. Impact of using the International Association of Diabetes and Pregnancy Study Groups criteria in South Auckland: prevalence, interventions and outcomes. Aust N Z J Obstet Gynaecol. 2015;55(1):34-41.

32. Helseth R, Salvesen O, Stafne SN, Morkved S, Salvesen KA, Carlsen SM. Gestational diabetes mellitus among Nordic Caucasian women: prevalence and risk factors according to WHO and simplified IADPSG criteria. Scand J Clin Lab Invest. 2014;74(7):620-8.

33.• Duran A, Saenz S, Torrejon MJ, Bordiu E, Del Valle L, Galindo M, et al. Introduction of IADPSG criteria for the screening and diagnosis of gestational diabetes mellitus results in improved pregnancy outcomes at a lower cost in a large cohort of pregnant women: the St. Carlos Gestational Diabetes Study. Diabetes Care. 2014;37:2442-50 This study concluded that $€ 14,358.06$ could be saved per 100 women using IADPSG versus CC to diagnose GDM. They estimated that the new criteria would increase treatment costs by $€ 3753.79$, but reduce laboratory costs by $€ 1587.76$, and further reduce delivery and NICU costs by $€ 16,336.90$. Most cost savings were related to a predicted reduction in CS and NICU admissions.

34. O'Sullivan EP, Avalos G, O'Reilly M, Dennedy MC, Gaffney G, Dunne FP. Atlantic DIP: the prevalence and consequences of gestational diabetes in Ireland. Ir Med J. 2012;105(5 Suppl):13-5.

35. Morikawa M, Yamada T, Yamada T, Akaishi R, Nishida R, Cho K, et al. Change in the number of patients after the adoption of IADPSG criteria for hyperglycemia during pregnancy in Japanese women. Diabetes Res Clin Pract. 2010;90(3):339-42.

36. Hirst JE, Tran TS, Do MA, Morris JM, Jeffery HE. Consequences of gestational diabetes in an urban hospital in Viet Nam: a prospective cohort study. PLoS Med. 2012;9(7):e1001272.

37. Savona-Ventura C, Vassallo J, Marre M, Karamanos BG. Hyperglycaemia in pregnancy in Mediterranean women. Acta Diabetol. 2012;49(6):473-80.

38. Sevket O, Ates S, Uysal O, Molla T, Dansuk R, Kelekci S. To evaluate the prevalence and clinical outcomes using a one-step method versus a two-step method to screen gestational diabetes mellitus. The journal of maternal-fetal \& neonatal medicine : the official journal of the European Association of Perinatal Medicine, the Federation of Asia and Oceania Perinatal Societies, the International Society of Perinatal Obstet. 2014;27(1):36-41.

39. Thapa P, Shrestha S, Flora MS, Bhattarai MD, Thapa N, Mahat B, et al. Gestational diabetes mellitus - a public health concern in rural communities of Nepal. J Nepal Health Res Counc. 2015;13(31): 175-81.

40. Wei Y, Yang H, Zhu W, Yang H, Li H, Yan J, et al. International Association of Diabetes and Pregnancy Study Group criteria is suitable for gestational diabetes mellitus diagnosis: further evidence from China. Chin Med J. 2014;127(20):3553-6.

41. Alfadhli E. Gestational diabetes in Saudi women identified by the International Association of Diabetes and Pregnancy Study Group versus the former American Diabetes Association criteria: a prospective cohort study. Annals of Saudi medicine. 2015;35(6):428-34.

42. Sibartie P, Quinlivan J. Implementation of the International Association of Diabetes and Pregnancy Study Groups criteria: not always a cause for concern. J Pregnancy. 2015;2015:754085.

43. Mayo K, Melamed N, Vandenberghe H, Berger H. The impact of adoption of the international association of diabetes in pregnancy study group criteria for the screening and diagnosis of gestational diabetes. Am J Obstet Gynecol. 2015;212(2):224-e1-9.

44. Seshiah V, Balaji V, Shah SN, Joshi S, Das AK, Sahay BK, et al. Diagnosis of gestational diabetes mellitus in the community. J Assoc Physicians India. 2012;60:15-7.

45. Kun A, Tornoczky J, Tabak AG. The prevalence and predictors of gestational diabetes mellitus in Hungary. Hormone and metabolic research $=$ Hormon- und Stoffwechselforschung $=$ Hormones et metabolisme. 2011;43(11):788-93.

46. Reyes-Munoz E, Parra A, Castillo-Mora A, Ortega-Gonzalez C. Effect of the diagnostic criteria of the International Association of Diabetes and Pregnancy Study Groups on the prevalence of gestational diabetes mellitus in urban Mexican women: a cross-sectional study. Endocrine practice : official journal of the American College of Endocrinology and the American Association of Clinical Endocrinologists. 2012;18(2):146-51.

47. Trujillo J, Vigo A, Duncan BB, Falavigna M, Wendland EM, Campos MA, et al. Impact of the International Association of Diabetes and Pregnancy Study Groups criteria for gestational diabetes. Diabetes Res Clin Pract. 2015;108(2):288-95.

48. Crowther CA, Hiller JE, Moss JR, McPhee AJ, Jeffries WS, Robinson JS. Effect of treatment of gestational diabetes mellitus on pregnancy outcomes. N Engl J Med. 2005;352(24):2477-86.

49. Waters TP, Dyer AR, Scholtens DM, Dooley SL, Herer E, Lowe LP, et al. Maternal and neonatal morbidity for women who would be added to the diagnosis of GDM using IADPSG criteria: a secondary analysis of the hyperglycemia and adverse pregnancy outcome study. Diabetes Care. 2016;39(12):2204-10. Untreated women with GDM by IADPSG criteria (excluding those who also met $\mathrm{CC}$ criteria) had increased preeclampsia, primary $\mathrm{CS}$, LGA, cord C-peptide, and newborn percentage body fat above the 90th percentile, indicating higher risk of adverse outcomes compared to women with NGT.

50. Ethridge JK Jr, Catalano PM, Waters TP. Perinatal outcomes associated with the diagnosis of gestational diabetes made by the international association of the diabetes and pregnancy study groups criteria. Obstet Gynecol. 2014;124(3):571-8.

51. O'Sullivan EP, Avalos G, O'Reilly M, Dennedy MC, Gaffney G, Dunne F. Atlantic Diabetes in Pregnancy (DIP): the prevalence and outcomes of gestational diabetes mellitus using new diagnostic criteria. Diabetologia. 2011;54(7):1670-5.

52. Lindqvist M, Persson M, Lindkvist M, Mogren I. No consensus on gestational diabetes mellitus screening regimes in Sweden: pregnancy outcomes in relation to different screening regimes 2011 to 2012, a cross-sectional study. BMC pregnancy and childbirth. 2014;14(1):185

53. Bodmer-Roy S, Morin L, Cousineau J, Rey E. Pregnancy outcomes in women with and without gestational diabetes mellitus according to the International Association of the Diabetes and Pregnancy Study Groups criteria. Obstet Gynecol. 2012;120(4):746-52.

54. Sacks DA, Black MH, Li X, Montoro MN, Lawrence JM. Adverse pregnancy outcomes using the International Association of the Diabetes and Pregnancy Study Groups criteria: glycemic thresholds and associated risks. Obstet Gynecol. 2015;126(1):67-73.

55. Black MH, Sacks DA, Xiang AH, Lawrence JM. Clinical outcomes of pregnancies complicated by mild gestational diabetes mellitus differ by combinations of abnormal oral glucose tolerance test values. Diabetes Care. 2010;33(12):2524-30. 
56. March MI, Modest AM, Ralston SJ, Hacker MR, Gupta M, Brown FM. The effect of adopting the IADPSG screening guidelines on the risk profile and outcomes of the gestational diabetes population. The journal of maternal-fetal \& neonatal medicine : the official journal of the European Association of Perinatal Medicine, the Federation of Asia and Oceania Perinatal Societies, the International Society of Perinatal Obstet. 2016;29(7):1141-5.

57. Pan L, Leng J, Liu G, Zhang C, Liu H, Li M, et al. Pregnancy outcomes of Chinese women with gestational diabetes mellitus defined by the IADPSG's but not by the 1999 WHO's criteria. Clin Endocrinol. 2015;83(5):684-93.

58. Kim C, Newton KM, Knopp RH. Gestational diabetes and the incidence of type 2 diabetes: a systematic review. Diabetes Care. 2002;25(10):1862-8.

59. Bellamy L, Casas JP, Hingorani AD, Williams D. Type 2 diabetes mellitus after gestational diabetes: a systematic review and metaanalysis. Lancet. 2009;373(9677):1773-9.

60. Noctor E, Crowe C, Carmody LA, Kirwan B, O'Dea A, Glynn LG, et al. ATLANTIC-DIP: prevalence of metabolic syndrome and insulin resistance in women with previous gestational diabetes mellitus by International Association of Diabetes in Pregnancy Study Groups criteria. Acta Diabetol. 2015;52(1):153-60. 75-g OGTTs at 12 weeks' postpartum in women with GDM based on the IADPSG criteria had $5.6 \%$ prevalence of glucose abnormalities (14.1\% IFG and/or IGT and 1.5\% DM2) compared to that of $0.8 \%$ of women with NGT. At repeat testing (mean follow-up of GDM of 2.6 years), another $10.4 \%$ of those with a history of GDM had developed abnormal glucose levels compared to only $\mathbf{2 . 8 \%}$ of those without history of GDM.

61. Bartakova V, Maluskova D, Muzik J, Belobradkova J, Kankova K. Possibility to predict early postpartum glucose abnormality following gestational diabetes mellitus based on the results of routine midgestational screening. Biochemia medica. 2015;25(3):460-8.

62.• Agarwal MM, Dhatt GS, Othman Y. Gestational diabetes in a tertiary care hospital: implications of applying the IADPSG criteria. Arch Gynecol Obstet. 2012;286(2):373-8. If an FPG < 4.4 $(80 \mathrm{mg} / \mathrm{dl})$ rules out GDM and $>5.1 \mathrm{mmol} / \mathrm{l}(92 \mathrm{mg} / \mathrm{dl})$ rules in GDM, then no additional testing is required. This avoids the need for $>50 \%$ of the OGTTs. The authors point out that in high-risk populations GCT adds an unnecessary screen and risks missing $20 \%$ with a false negative screen as well as those who do not show for the second step OGTT (18\% in this study).

63. Mission JF, Ohno MS, Cheng YW, Caughey AB. Gestational diabetes screening with the new IADPSG guidelines: a cost-effectiveness analysis. Am J Obstet Gynecol. 2012;207(4):326-e1-9.

64. Werner EF, Pettker CM, Zuckerwise L, Reel M, Funai EF, Henderson J, et al. Screening for gestational diabetes mellitus: are the criteria proposed by the International Association of the Diabetes and Pregnancy Study Groups cost-effective? Diabetes Care. 2012;35(3):529-35.

65. Weile LK, Kahn JG, Marseille E, Jensen DM, Damm P, Lohse N. Global cost-effectiveness of GDM screening and management: current knowledge and future needs. Best practice \& research Clinical obstetrics \& gynaecology. 2015;29(2):206-24.

66. Standards of medical care in diabetes - 2011. Diabetes Care. 2011;34 Supp1 1:S11-61.

67. Blumer I, Hadar E, Hadden DR, Jovanovic L, Mestman JH, Murad $\mathrm{MH}$, et al. Diabetes and pregnancy: an endocrine society clinical practice guideline. J Clin Endocrinol Metab. 2013;98(11):4227-49.

68. WHO Guidelines Approved by the Guidelines Review Committee. Diagnostic criteria and classification of hyperglycaemia first detected in pregnancy. Geneva: World Health Organization Copyright (c) World Health Organization 2013; 2013.

69. Committee opinion no. 504: screening and diagnosis of gestational diabetes mellitus. Obstetrics and gynecology. 2011;118(3):751-3.

70. Practice bulletin no. 137: gestational diabetes mellitus. Obstetrics and gynecology. 2013;122(2 Pt 1):406-16.

71. Report of the expert committee on the diagnosis and classification of diabetes mellitus. Diabetes Care. 1997;20(7):1183-97.

72. Williams CB, Iqbal S, Zawacki CM, Yu D, Brown MB, Herman WH. Effect of selective screening for gestational diabetes. Diabetes Care. 1999;22(3):418-21.

73. Avalos GE, Owens LA, Dunne F. Applying current screening tools for gestational diabetes mellitus to a European population: is it time for change? Diabetes Care. 2013;36(10):3040-4.

74. Hughes RCE, Moore MP, Gullam JE, Mohamed K, Rowan J. An early pregnancy $\mathrm{HbAlc} \geq 5.9 \%(41 \mathrm{mmol} / \mathrm{mol})$ is optimal for detecting diabetes and identifies women at increased risk of adverse pregnancy outcomes. Diabetes Care. 2014;37(11):2953-9.

75. Zhu W-w, Yang H-x, Y-m W, Yan J, Wang Z-1, X-1 L, et al. Evaluation of the value of fasting plasma glucose in the first prenatal visit to diagnose gestational diabetes mellitus in China. Diabetes Care. 2013;36(3):586-90.

76. Alunni ML, Roeder HA, Moore TR, Ramos GA. First trimester gestational diabetes screening - change in incidence and pharmacotherapy need. Diabetes Res Clin Pract. 2015;109(1):135-40.

77. Yeral MI, Ozgu-Erdinc AS, Uygur D, Seckin KD, Karsli MF, Danisman AN. Prediction of gestational diabetes mellitus in the first trimester, comparison of fasting plasma glucose, two-step and one-step methods: a prospective randomized controlled trial. Endocrine. 2014;46(3):512-8.

78. Schousboe K, Henriksen JE, Kyvik KO, Sorensen TI, Hyltoft PP. Reproducibility of S-insulin and B-glucose responses in two identical oral glucose tolerance tests. Scand J Clin Lab Invest. 2002;62(8):623-30.

79. Donovan L, Hartling L, Muise M, Guthrie A, Vandermeer B, Dryden DM. Screening tests for gestational diabetes: a systematic review for the U.S. Preventive Services Task Force. Ann Intern Med. 2013;159(2):115-22.

80. Wei YM, Yang HX, Zhu WW, Yang HY, Li HX, Kapur A. Effects of intervention to mild GDM on outcomes. The journal of maternalfetal \& neonatal medicine : the official journal of the European Association of Perinatal Medicine, the Federation of Asia and Oceania Perinatal Societies, the International Society of Perinatal Obstet. 2015;28(8):928-31.

81. Trujillo J, Vigo A, Reichelt A, Duncan BB, Schmidt MI. Fasting plasma glucose to avoid a full OGTT in the diagnosis of gestational diabetes. Diabetes Res Clin Pract. 2014;105(3):322-6.

82. Sevket O, Sevket A, Ozel A, Dansuk R, Kelekci S. The use of $\mathrm{HbA} 1 \mathrm{c}$ as an aid in the diagnosis of gestational diabetes mellitus. Journal of obstetrics and gynaecology : the journal of the Institute of Obstetrics and Gynaecology. 2014;34(8):690-2.

83. Hod M, Kapur A, Sacks DA, Hadar E, Agarwal M, Di Renzo GC, et al. The International Federation of Gynecology and Obstetrics (FIGO) initiative on gestational diabetes mellitus: a pragmatic guide for diagnosis, management, and care. International journal of gynaecology and obstetrics: the official organ of the International Federation of Gynaecology and Obstetrics. 2015;131(Suppl 3): S173-211.

84. Catalano PM, Vargo KM, Bernstein IM, Amini SB. Incidence and risk factors associated with abnormal postpartum glucose tolerance in women with gestational diabetes. Am J Obstet Gynecol. 1991;165(4 Pt 1):914-9. 